Deborah Hellman

\title{
When Is Discrimination Wrong?
}

HARVARD UNIVERSITY PRESS

Cambridge, Massachusetts, and London, England 
Copyright $\odot 2008$ by the President and Fellows of Harvard College All rights reserved

Printed in the United States of America

First Harvard University Press paperback edition, 2011

Library of Congress Cataloging-in-Publication Data

Hellman, Deborah, 1963-

When is discrimination wrong? / Deborah Hellman.

p. $\mathrm{cm}$.

Includes bibliographical references and index.

ISBN 978-0-674-02797-8 (cloth: alk. paper)

ISBN 978-0-674-06029-6 (pbk.)

1. Discrimination. 2. Interpersonal relations. 1. Title.

HM1 106.H42 2008

$305-\mathrm{dc} 22$ 
For my parents, Rusty and Sam Hellman,

who encouraged me at every step,

and talked me through each argument.

For my husband, Derek Brown,

for being so extraordinarily flexible and supportive and for everything else. 


\section{Contents}

Introduction: The Discrimination Puzzle $\quad 1$

\section{When Is Discrimination Wrong?}

1 The Basic Idea 13

2 Demeaning and Wrongful Discrimination 34

3 Interpretation and Disagreement 59

\section{Considering Alternatives}

Introduction to Part II 89

4 Merit, Entitlement, and Desert 93

5 Accuracy and Irrationality 114

6 Is It the Thought that Counts? 138

Conclusion 169

Notes 175

Acknowledgments 201

Index 203 


\section{Introduction: The Discrimination Puzzle}

A law requires black bus passengers to sit in the back of the bus and white passengers to sit in the front.

A school principal asks the students with last names beginning with A-M to sit on the left side of the auditorium and those with last names beginning with $\mathrm{N}-\mathrm{Z}$ to sit on the right side.

An employer at a casino requires female employees to wear makeup and prohibits male employees from wearing makeup.

A nursing home with a predominantly female clientele refuses to hire a male nurse's aide for a job requiring assisting residents with bathing and toilet needs.

A personal advertisement under "Men Seeking Women" in a local paper reads: "Looking for a single woman, age 30-40, for a long-term relationship or marriage. Seeking a woman who is not afraid to be feminine.

Prefer someone slim, who wears makeup and likes to dress fashionably."

A worker who is biologically male but dresses and lives as a female requests that her employer designate some bathrooms as unisex or alternatively allow her to use the women's bathroom. The employer refuses and instructs the employee to use the men's bathroom. The employee refuses and is fired as a result.

The U.S. Food and Drug Administration approves a drug specifically for use by African American heart failure patients. 
A public school's "gifted and talented program" and a selective private school screen kindergarten admissions according to children's IQ test scores.

A university in Iran uses political affiliation as a criterion for selecting students and faculty.

A business prefers to hire job applicants from the local community.

An airline refuses to continue to employ pilots older than 62 .

A state refuses to license drivers under age 16.

A company prefers not to hire women between the ages of 20 and 40 .

Each example above draws a distinction between people on the basis of a certain trait: race, the first letter of the person's last name, sex, appearance, ability, age, or another attribute. Our intuition suggests that while some of these laws, policies, or practices are morally wrong, some are benign, and the nature of still others is unclear. The aim of this book is to examine why it is sometimes permissible and sometimes impermissible to draw such distinctions among people. In other words, the aim here is to present a general theory of discrimination.

The term discrimination has come to have a negative connotation. To call something "discrimination" is to criticize it, to assert that it is wrong. But of course the term has positive associations as well. One can be complimented for discriminating taste (in art, wine, literature, etc.). Someone who is astute and has a subtle mastery of his subject is often described as "discriminating," as in "the manager of the mutual fund is very discriminating in his investments." This positive use of the term is more marginal, however, overwhelmed by its negative associations with wrongful discrimination. By resurrecting it here, I do not mean to downplay the harms of wrongful discrimination. Rather, I want to emphasize the positive as well as the negative aspects of discrimination in order to unsettle our certainty about which instances of discrimination are wrong and especially about whether we know why they are wrong.

Discrimination-used in this way that captures both its negative and its positive connotations-is both ubiquitous and necessary. We routinely 
draw distinctions among people in public policy and law as well as in business, school settings, and private life. Laws require that drivers must be a certain age (16 is common) and must pass a test to be licensed to drive in all states. These laws distinguish (i.e., discriminate) between people on the basis of age and their ability to pass a test; they treat those 16 and over who have passed the driving test more favorably (they are allowed to drive) than the group of people who are either under 16 or have failed the driving test. Employers and school admissions officials draw distinctions among applicants on the basis of grades, test scores, and myriad other, sometimes quite controversial, traits. Some firms are in the very business of discrimination: Insurers draw distinctions among people on the basis of traits that reflect the likelihood that the insured will file a claim during the policy period. For example, health and life insurers distinguish among people on the basis of health status-people with high blood pressure, who are overweight, and who smoke will pay more for health and life insurance (if they can get insurance at all) than non-smokers with low blood pressure and average weight. Private and family life calls for discrimination as well. A mother who puts her 2-year-old daughter in her crib for an afternoon nap but allows her 4-year-old to continue playing is drawing a distinction between her children on the basis of age-and is limiting the freedom of the 2-year-old in a way that she is not limiting that of the 4-year-old.

Much of this distinction drawing is important or even unavoidable. While we could treat everyone the same in some of the instances described above, there would be a significant cost in doing so. To take the last and perhaps most mundane example first, if the mother were to treat both her children the same, she would have to either put both down for naps or allow both to play all afternoon. Any parent of a 2-year-old could tell you that this latter suggestion is folly. Come about four or five o'clock, the 2-year-old would be miserable, as would anyone within earshot of the child. If the mother were to put both children down for a nap, there are a number of not very appealing scenarios that might ensue. One cannot make a child sleep, so merely putting a child to bed doesn't mean she will sleep. She may simply yell, cry, and require continuous parental intervention to stay in the bedroom. Alternatively, she may fall asleep. The problem with this outcome is that she would then be unable to fall asleep at a reasonable bedtime that night, which would leave her tired the next day and her parents with no time for themselves at night. While a well-behaved child might simply play 
quietly in bed, it seems unreasonable-at least I think so-to insist that she do so merely because her sibling needs a nap.

In the case of laws and public policies that distinguish among people, the stakes are much higher. I doubt that we would be willing to either license all drivers regardless of age or to bar everyone from driving-the two options that would treat everyone the same. Nor would we be willing, I imagine, to license anyone who wanted to practice law or medicine regardless of whether the person had passed the tests demonstrating the requisite knowledge and skill.

Finally, where there are limited openings, for jobs or places at school, for example, it is simply not possible to treat one and all the same. Not everyone can be hired or admitted. Thus, we must draw distinctions among the applicants on some basis. The question then becomes, when is such distinction-drawing morally problematic and when is it not?

This book will address the moral question posed by the fact that it is often desirable and sometimes necessary to treat people differently. Laws govern when it is legally permissible to do so, either in the form of local, state-wide, or national statutory prohibitions on discrimination of various types or, in the United States, in the form of judicial interpretation of the constitutional guarantee of Equal Protection. While in some ways one could view this statutory and constitutional law as itself providing an answer to the question of when it is morally permissible to draw distinctions among people, there are other important issues that play a role in determining when something ought to be legally prohibited. Some things that are morally wrong are not legally prohibited, and for good reason (being mean to others, for example). And some things are legally prohibited that are not morally wrong, except to the extent that it is wrong to break the law (driving without a license, for example). And yet, perhaps because the U.S. constitutional guarantee of equal protection is itself vague and open to interpretation, much of the legal debate-in this country and elsewhere-has a moral cast. For that reason, the legal literature provides an important starting point for wrestling with what I call the discrimination puzzle.

The fact that we often need to distinguish among people forces us to ask when discrimination is morally permissible and when it is not. This puzzle has no easy answer. While people may have a fairly settled sense that certain instances of drawing distinctions among people on the basis of particular traits in particular contexts are wrong, it is harder than one might expect 
to explain what makes these cases wrong in a way that also works to explain other cases of wrongful and permissible discrimination.

One might think that drawing distinctions on the basis of certain traits is always forbidden-race and sex, in particular. But if so, does that mean that the U.S. Food and Drug Administration (FDA) necessarily acts wrongly in approving a particular drug for use by African American patients? And does it mean that single-sex bathrooms are clearly impermissible? While there may be problems with each of these practices, which we will discuss in later chapters, I don't think either one could be easily written off as impermissible based solely on the fact that it discriminates on the basis of race or sex respectively.

Another facet of the discrimination puzzle that makes it difficult to untangle is that wrongful discrimination sometimes occurs in contexts where the difference in treatment seems unimportant. Nelson Mandela reports in his autobiography that the apartheid regime in South Africa required black prisoners to wear shorts while white and colored prisoners were required to wear pants. In the heat of southern Africa, shorts might be the more comfortable option. Nonetheless, the symbolism of being required to wear shorts, which were commonly seen as infantilizing in this postcolonial regime, was a means of demeaning black prisoners. On the other hand, distinguishing among and treating people differently may deny some an important benefit or opportunity, and yet seem perfectly permissible. An employer might choose the person who types the fastest with the fewest errors for a word-processing job, for example. This policy distinguishes among job applicants on the basis of typing speed and skill and as a result treats one group (the slower typists) far less favorably (they lose out on a well-paid job) than the other (faster typists). So the fact that someone or some group is denied something important, like a good job, doesn't provide a clue as to whether the discrimination is wrongful or permissible.

One might think that one could easily explain why the first of these two cases is impermissible and the second permissible (conclusions I share) by looking at some obvious differences between them. First, in the case of the South African prison garb, the policy was likely imposed to stigmatize black prisoners, while the typing requirements were set for the benign purpose of increasing the productivity of the employer's business. Second, skin color is irrelevant to what uniform prisoners ought to wear, while typing speed and accuracy are relevant to the job of a typist. ${ }^{1}$

Do these differences matter morally? Sometimes morally troubling policies are enacted with the same intention as that of the employer who selects 
the best typist - that is, to enhance business productivity. Suppose an employer refuses to hire women between the ages of 20 and 40 on the grounds that they are likely to take time off to have children, which would disrupt work schedules and raise the business's medical costs. The employer might adopt this policy merely to enhance business productivity, but does this benign intention insulate the policy from moral criticism?

The fact that a trait is "relevant" or "irrelevant" also fails to distinguish permissible from impermissible discrimination. In the previous example, sex is a relevant job qualification if by "relevant" we simply mean that it is positively correlated with something important. Here sex is likely correlated with work schedules and the costs of childbearing, as the employer supposes. If relevance is merely a matter of the fit between a distinguishing trait and a target, like efficiency, and such relevance is what matters morally, then many practices that our intuitions suggest are morally problematic would be deemed legitimate-like employers refusing to hire women of child-bearing age.

Perhaps the concept of relevance can be refined. The prison-garb case and the typist case differ in that the typist merits the job whereas the white prisoners do not merit long pants. Doesn't the idea of merit then provide an answer to at least some discrimination puzzles? I think not. Consider the employer who gives a preference to local job candidates in order to support the local community in which she is based. Do the locals thereby merit the jobs? The concept of merit is itself contested such that it will be unlikely to resolve questions regarding what is wrongful discrimination.

In attempting to answer the question posed by the discrimination puzzle, I begin with what I consider a bedrock moral principle-the equal moral worth of all persons. I take it that this bedrock principle is comprised of two sub-principles: First, there is a worth or inherent dignity of persons that requires that we treat each other with respect. What violates this principle may be contested (and is something that the argument of this book will address), but I will assume that the inherent worth of a person sets moral limits on how others may treat her. Second, this inherent dignity and worth of all persons does not vary according to their other traits. While some people are smarter, faster, and more talented at tasks that benefit others, or even kinder and more gentle, these and other differences do not affect how important each of us is from a moral perspective. The inherent worth of persons is not something that comes in degrees. Rather, all people are equally important from the moral point of view and so are equally worthy of concern and respect. ${ }^{2}$ 
I begin with this bedrock principle because I suspect the moral concern that fuels our worries about drawing distinctions among people is that in doing so we may act in ways that fail to treat others as equally worthy. The discrimination puzzle asks when it is morally permissible to draw distinctions among people on the basis of some trait that they have or lack. We can further refine that question, in recognition of the fact that our concern springs from our commitment to the principle of equal moral worth, and ask, when does drawing distinctions among people fail to treat those affected as persons of equal moral worth? It is this question that this book will address.

It is important to emphasize here the conventional and social nature of wrongful discrimination. We all have many traits: race, age, sex, appearance, abilities, height, weight, voice tone, our names, religion, and so on. As simply traits, they are inert. What matters about them is their social significance in particular contexts. Drawing distinctions on the basis of certain traits in certain contexts has meaning that distinguishing on the basis of other traits would not. Separating students by last name feels quite different than separating students by race, for example-though each can be done for good or bad reasons and each may be related or unrelated to some legitimate purpose. In addition, drawing distinctions among people on the basis of the same trait in different contexts feels different as well. As Justice Marshall once observed: "A sign that says "men only" looks very different on a bathroom door than on a courthouse door." 3 It "looks very different" not because women can practice law as well as men. After all, women can also use men's bathrooms as well as men, too. Nor does the fault lie in the fact that the law prohibiting women from practicing law was enacted in order to keep women out or was grounded in stereotypes about men and women. The prohibition of women from the men's bathroom was also enacted to keep women out and is based on stereotypes about men and women (and privacy norms concerning certain bodily functions). Rather, the problem with the courthouse prohibition is that it distinguishes between men and women in a way that demeans women whereas the bathroom prohibition does not.

Part I builds the argument that it is morally wrong to distinguish among people on the basis of a given attribute when doing so demeans any of the people affected. Chapter 1 lays out the argument for this account of wrongful discrimination. Whether a particular distinction does demean is determined by the meaning of drawing such a distinction in that context, in 
our culture, at this time. In focusing on whether a distinction demeans, this account does not rest on the consequences or the effects of a classification. Rather, some classifications demean-whether or not the person affected feels demeaned, stigmatized, or harmed. As such, this account of wrongful discrimination grounds moral impermissibility in the wrong rather than the harm of discrimination.

Chapter 2 develops the argument by exploring in more detail what "demeaning" is and why it is important. It begins by explaining why actions that distinguish among people in a way that demeans are thereby wrongful. The chapter argues that because to demean is to treat another in a way that denies her equal moral worth, it picks out a wrong that is intimately tied to the value that underlies our moral concern with differentiation in the first place. The chapter then provides a more detailed account of "demeaning": to demean is both to express denigration and to do so in a way that has the power or capacity to put the other down.

Chapter 3 explores the important questions of how we determine whether drawing a particular distinction in a particular context does demean and whether the fact that people will likely disagree about whether particular distinctions demean is problematic for the theory I advance.

Part II explores some common answers to the discrimination puzzle and argues that each is ultimately unsatisfactory. Chapter 4 considers the concept of merit and argues that it cannot separate permissible from impermissible discrimination. The concept of merit is unable to help because any discussion about whether drawing a particular distinction in a particular context is permissible can simply be recast as a debate about what constitutes merit in that context. For example, universities in Iran use political affiliation as a criterion in selecting students and professors. One might think that this practice constitutes wrongful discrimination because these students and professors don't merit their positions. But why not? The university administrators surely believe that the best students and teachers are those with the best moral values-as they define them. In other words, critics and supporters of this policy can best be understood as arguing about what constitutes merit in a university context. If so, the concept of merit itself will not be useful in sorting out permissible from impermissible discrimination.

Chapter 5 argues against the moral relevance of the accuracy of classification. One might think that if one distinguishes among people on the basis of, say, age, in determining who is able to apply for a driving license, 
that it should matter morally whether age is indeed a good predictor of driving ability. If it is not, then perhaps there is something problematic about using it. There is surely something problematic about using age if it is unrelated to driving ability, but the relevant question is whether that something is a moral concern or merely a pragmatic one. Chapter 5 contends that the use of inaccurate classification is inefficient and stupid but not a moral wrong.

Finally, Chapter 6 argues against the view that it is the intention of the person who draws a distinction that is important. This chapter considers two arguments for the relevance of intentions: First, one might think that the actor's intention determines whether an actor in fact distinguishes on the basis of a particular trait or not. Second, one might think that distinguishing among people for a bad purpose renders the action morally suspect. In this chapter I argue against each of these claims, concluding that as far as discrimination goes, it's not the thought that counts.

The book concludes by exploring the ways in which the conception of wrongful discrimination I advance has affinities with the recent emphasis of moral philosophers on the importance of equality of respect when considering what the equal moral worth of persons requires. 
PART I

When Is Discrimination Wrong? 
CHA P TER 1

\section{The Basic Idea}

We routinely draw distinctions among people on the basis of characteristics they possess or lack. This practice is ubiquitous and commonplace. Moreover, much of it-perhaps most-is morally permissible or benign. Some of it however is morally troubling, even deeply so. What explains this difference?

\section{“Discrimination"}

I put the term discrimination in scare quotes because there is an important ambiguity in the term. Discrimination can be used in a descriptive or moralized way. Descriptively, to "discriminate" is merely to draw distinctions among people on the basis of the presence or absence of some trait. For example, the requirement that one must be at least 16 to drive discriminates between people under 16 and people 16 and over. The requirement that one must pass the bar exam to practice law discriminates between those who pass the bar and those who do not. When the term discrimination is used in a moralized way, it means to wrongfully draw such distinctions. For example, state laws that required separate seating for black and white passengers on buses and trains wrongfully discriminated between passengers on the basis of race. To avoid confusion about which sense of discrimination I am discussing, I will try to avoid using the words discriminate and discrimination standing alone. Instead, perhaps forfeiting elegance for clarity at times, when I have in mind the descriptive sense of discrimination, I will say that the law, policy, or action "classifies," or "draws a distinction" or "distinguishes" on the basis of X trait, or something similar. When I have in mind the moralized sense of discrimination, I will say that the law, policy, or action "wrongfully discriminates" so that the moral judgment is explicit. 


\section{Motivating the Idea}

I want to begin with an artificial and unlikely example. Suppose an employer or a school admissions official were to decide to refuse to hire or admit any candidate whose last name begins with the letter A. On this basis, Adams is rejected. Is this wrongful discrimination? The claim I want to advance in this chapter is that there is nothing wrong with this decision-at least nothing wrong that violates the principle of the equal moral worth of persons. Rejecting Adams because his name begins with $\mathrm{A}$ is therefore not wrongful discrimination.

Contrast that example with another. Suppose an employer or school admissions official refuses to hire or admit women. What makes this case different? One salient difference between drawing distinctions on the basis of sex as compared to the first letter of a person's last name is that our society as well as others has a long history of treating women poorly. There are extreme examples of this mistreatment such as disenfranchisement, laws prohibiting women from owning property, laws that defined rape in ways that excluded a husband's rape of his wife from the prohibited conduct, etc. One can obviously go on. There is clearly no comparable history of mistreating people whose last names begin with the letter A. In addition, women currently have a lower socioeconomic status than men in most areas of the world whereas people whose names begin with A are, as far as I know, no more or less well off than those whose names begin with the other twenty-five letters of the alphabet. Women today continue to earn less than men, to be dramatically overrepresented among the poor, and to be vulnerable to violence in the home. My goal is not to establish these facts, which have been more than amply demonstrated by others, and are, I hope, not controversial. Rather, I want to sketch an argument for why these facts matter.

The view that a history of mistreatment and the current social status of people with a particular characteristic are relevant to whether instances of differentiation are wrong is itself not terribly controversial. Courts, commentators, and scholars have made this point before. The interesting question to untangle is why and how history and current social status matters.

Here are some possible answers to that question:

1. The ideal of equality prohibits a certain state of affairs-one in which caste-like distinctions among people exist. According to this view, 
refusing to hire or admit someone on the basis of sex is wrong because it risks reinforcing or exacerbating the male hierarchy of our society.

2. The systemic disadvantaging of women matters when evaluating a policy that distinguishes among people on the basis of sex because, as a group, women are likely to have been either entirely excluded from the processes through which the policy was adopted or to have had their interests discounted in that process.

3. The history of mistreatment and the current status of women in society both matter because they determine the nature of an action refusing to hire or admit a woman because of her sex. Being denied a job on the basis of being female demeans women in a way that being denied a job because one's last name begins with A does not.

There are surely other theories about why or how the history and current social status of a particular group matters. I concentrate on these because theory 1 roughly articulates Owen Fiss's anti-caste understanding of the Equal Protection Clause and theory 2 reconstructs John Hart Ely's account of when courts ought to scrutinize enactments under the Equal Protection Clause. ${ }^{1}$ Given the prominence-even many years later-of Ely's and Fiss's accounts and the role that legal and jurisprudential understandings of that clause play in both popular and academic debates about when drawing distinctions among people is morally permissible and when it is not, their accounts seem worthy of note. The third proposition, by contrast, is the view I intend to argue for in this chapter.

\section{Wrongful and Discrimination but Not Wrongful Discrimination}

So far I imagine most readers would agree that there is a difference between refusing to hire or admit Adams because her last name begins with A and refusing to hire or admit a woman because of her sex. However, though one might agree that history does make a difference-perhaps making one differentiation worse than the other-one might object to the perhaps counterintuitive suggestion that Adams suffers no wrongful discrimination. In order to make that view more plausible, let me make clear that there may well be something wrong with the fact that the employer or school admissions official refuses to take Adams because her name begins with A. But while it 
may be wrong to deny someone a place for this reason, it is not a wrong that offends against the norm of equality and thus is not wrongful discrimination.

Denying someone a job or place at school because her name begins with the letter A could be wrong for an entirely different reason. For example, a law school admissions official may have certain criteria that she is supposed to apply, as provided to her explicitly by the faculty committee charged with determining admissions criteria. If the official uses the first letter of the candidate's last name, in addition to or in lieu of these established criteria, she acts wrongly. This action is wrong because she has acted outside of her delegated authority, has failed to do what she promised to do, or something of this nature. We can criticize her action for these reasons without thereby concluding that Adams has been wrongly discriminated against. So part of what seems troubling about denying someone a job or place at school because of the first letter of her last name may be that there are constraints on the criteria that the official is supposed to use, constraints that derive from her obligation to fulfill her role in the organization.

Consider another example: Zora, a university student, signs up for a poetry class which has limited enrollment. She is rejected. She suspects that the teacher denied her admission because her father (a professor at the university) had previously had an affair with the poetry teacher. ${ }^{2}$ Has Zora been wrongly discriminated against? The poetry teacher, call her Professor Malcolm, draws a distinction between students who are related to people with whom she has been sexually involved and students who are not. Malcolm then treats the first group less favorably (denying them entry into class) than the second. Is this distinction-drawing wrong? If so, on what grounds?

One reason Malcolm's denying Zora entry might be wrong is that it goes against the internal rules or codes of the university-either those that are explicitly stated or those that are implicit in its values and mission. University professors are no doubt supposed to exercise their discretion to admit or deny students entry into their classes in a way that is consistent with the university's goals and values. If this is a class in poetry, the teacher should choose the most promising poetry students, perhaps. Even if the university's rules and values do not mandate that criterion, they no doubt forbid the criterion Malcolm used. In this regard, her action is wrongful. But what kind of wrong is this? Malcolm has acted in a way that her job requirements or role as a university professor forbids. She has violated the rules and 
obligations that the university lays down for its faculty. If we understand this wrong as one that offends the rules of conduct that the university has enacted, then it is a wrong analogous to using her office phone to make lengthy personal calls. If we understand the wrong as one that offends the values internal to the role of "university professor," then it is a wrong analogous to plagiarism. Perhaps it is a bit of both. Either way, though wrongful and discrimination, it is not wrongful discrimination. This is because the source of the wrongfulness does not have anything to do with failing to treat each person as a person of equal moral worth. Rather, the source of the wrong is the violation of the university's internal rules or values-ones that could be otherwise if it were a different sort of institution.

And what if it were a different sort of institution? What if the university officially sanctioned the use of such criteria in selecting students for entry into classes? Would that be wrong? And if so, on what basis?

Consider another example. In Reading Lolita in Tehran, Azar Nafisi reports that after the Iranian revolution, universities began accepting students on the basis of political affiliation rather than academic performance or scholarly promise. ${ }^{3}$ Is this wrongful discrimination? This case differs from Zora's in that here the admissions officials are not violating official university policy. In that sense, they are (we assume) neither acting outside of their roles nor violating the standards laid down by those with authority within the university. Rather, the university officials have changed the admissions standards to include political affiliation as one of the criteria that admissions officials must consider. So the admissions officials do not commit the wrong of violating the obligations of their role (as admissions officials) or of ignoring the admissions criteria adopted by the university. That is not the wrong they commit - as was the case with Professor Malcolm. Have they done anything else wrong? Nafisi seems to think so. She thinks there is something terribly wrong in using political affiliation as an admissions criterion at a university. But what exactly?

As I will argue in more detail in Chapter 4, which discusses merit and its relationship to wrongful discrimination, Nafisi's objection can best be understood as resting on an argument about what a university is. She sees a university as committed to the values of teaching and scholarship and thus sees the new criterion as a violation of these values. Is then the university's decision to change its admissions criteria wrongful discrimination? The first thing to note is that Nafisi and the university officials are debating precisely whether the criterion is acceptable or not. Is a political affiliation 
admissions criterion compatible with the mission of a university rightly understood? Second, if Nafisi is right and the criterion is incompatible, this makes the rejection of the better-qualified candidates wrong but does not thereby make it wrongful discrimination. As with Zora, the source of the wrong is not an offense to the norms of equality. Rather, the source of the wrong is the incompatibility of the political-affiliation criterion with the best understanding of the aims of a university. ${ }^{4}$

Consider one final example: genetic discrimination. People with certain known genetic mutations are more likely to develop particular diseases than people without them. Should insurance companies be allowed to either deny coverage or charge higher rates to people with genetic mutations that predispose them to disease? A person might hold the view that justice demands that everyone have health insurance. If so, drawing distinctions between insurance applicants on the basis of their genetic traits is wrong for reasons unrelated to equality. For such a person, genetic discrimination is no more or less wrong than other ways in which health insurance providers distinguish among customers. If so, then the wrongfulness of denying someone insurance because of a genetic mutation would lie not in a violation of the norm of equality but rather in a violation of the demands of justice. This is not wrongful discrimination. It is wrongful and it is discrimination (in the nonpejorative sense of drawing distinctions) but the wrong does not arise from the differentiation, rather it arises from the denial of what justice demands. ${ }^{5}$

When we differentiate among people and treat them differently as a result, it is thus possible for this act to be (a) permissible or (b) impermissible for reasons unrelated to the moral concerns underlying our worries about classification, or (c) impermissible because it offends the principle of the equal moral worth of persons. By giving readers a sense of how a classification could be wrongful, yet not wrongful discrimination, I hope to begin to answer doubts about my claim that refusing to hire Adams because her last name begins with A is not wrongful discrimination. There may well be something wrong with such an act-that depends on the criteria adopted by the institutions involved and the internal values that ought to guide their choice of criteria-but it is not the wrong of wrongful discrimination. ${ }^{6}$

Let me tie this point back to the moral principle with which I began-the equal moral worth of persons. If each person has an inherent worth, there are things one could do to her that would violate or deny that worth that have nothing to do with a concern for equality. If $\mathrm{X}$ kills $\mathrm{Y}$, he fails to respect 
her inherent worth-but there is not an equality issue here. If X kills some people and not others, he fails to respect their inherent worth and perhaps does so in a way that offends against the norm of equality, in that he selectively kills. However, in such a context we are unlikely to focus on the equality issue, as the killing itself is such a heinous violation of rights (inherent worth). But what of contexts where there is no right at issue other than the right to be treated as an equal? Here it is the value of equality that is most salient. Suppose there are many apartment seekers who want the same apartment and only one can get it. The inherent worth of a person is not violated by not getting the apartment. However, the equal worth of a person may be offended by the selection criteria used-whites only, for example. Where the problem lies in the selection criteria themselves, rather than in the failure to provide a good or a service, there is a potential equality problem.

But not all selection criteria do raise equality issues. Sometimes the failure to use particular selection criteria conflicts with norms or standards that derive from sources specific to the institution itself. In Zora's case, for example, the university has norms and values that guide its operations and the conduct of its faculty. What underlies these norms and values is a conception of the university itself and the sorts of standards appropriate to it. When selection criteria used to distinguish among people conflict with the internal standards of an institution, then the wrongness of distinguishing on such grounds resides in its conflict with the institution's goals and valuesrather than with the commitment to people's equal moral worth.

Distinctions that conflict with an institution's (or an individual's) own goals and values can constitute serious wrongs. I carve these off not to suggest they are unimportant. However, where a classification conflicts with internal values or goals, the institution or individual can choose to modify those values or goals to obviate the conflict. This consistency requirement is not an empty check, but its availability means that institutions or individuals can determine for themselves which selection criteria to use-unless there are limits that come from elsewhere. If people are of equal moral worth, then a commitment to this principle requires that we not draw distinctions among people in a manner that fails to treat them as moral equals.

Before moving on, I want to consider one more reason one might be concerned about distinguishing among people. Suppose a college admissions officer was to deny admission to applicants whom he or she did not find likable. Here I am not asking whether in fact the school has permitted or 
prohibited likability as a factor to be considered in the admissions process. If the school has prohibited it, and the official uses that factor in decisionmaking anyway, then she clearly violates the obligations of her role or employment contract. Rather, we are looking at the more fundamental question of whether likability is the sort of quality that, when officially authorized, nonetheless constitutes wrongful discrimination.

On what basis might one object to this criterion? One possibility is the one considered above-that likability is not the sort of quality a university ought to be concerned about. This objection, as I argued above, is best conceived as resting on what a university is and is thus focused on determining what sorts of values it can adopt while still remaining a university. What does being a university require? But are there other grounds to object? I imagine that someone might object that the criterion of likability is too subjective. But what does that mean exactly? It might mean that it is too dependent on the individual tastes of the person applying the criterion. If multiple people must apply the criterion, the sorts of people identified as likable could vary dramatically. This is a problem if one values uniformity. But is it a deep problem if one does not? If different officials, using the likability criterion, select applicants with different sorts of attributes, the worst one can say about this is that the selection criteria are arbitrary or irrational. This is an important concern, as many people believe that arbitrariness itself is morally significant. Indeed, the Supreme Court's Equal Protection doctrine requires-at least in theory-that classifications be rational, and thus seemingly endorses the moral relevance of rationality. ${ }^{7}$ In my view, the irrationality of classifications is not a wrong that has its roots in the norm of equality-the concern with the equal moral worth of persons-because we are all equally at risk of suffering from arbitrary treatment. It is a reason to get rid of the idiots (to vote them out or whatever) who adopt irrational criteria, but no more. But this is an argument that must be developed in detail. Chapter 5 takes up this task.

In claiming that a likability test is too subjective, one might have an entirely different worry. One might worry that people who are deemed unlikable will not form an arbitrary assemblage but rather will fall into some socially salient group-perhaps even a group that historically has been mistreated or that currently occupies a lower socioeconomic status. For example, Jews might be excluded on the grounds that they are not likable, if we imagine that establishmentarian WASPs are making the judgments. ${ }^{8}$ If this example seems outdated, one could easily imagine another, more 
current scenario. In such a case, the worry is not that likability itself ought not to be the basis for excluding people, but rather that, under the guise of considering likability, we are really excluding people based on religion or ethnicity. In other words, to gin up a criterion that offends against the norm of equality, we need to imagine not just that someone is excluded for a reason that seems unrelated to the institution's goals but instead that the exclusion is really based on a trait that defines a group with either a history of mistreatment or a lower social status currently.

Perhaps likability still seems a troubling admissions criterion to some readers. I use it as an example because it is one that many people are likely to find troubling. And it is troubling. But what makes it troubling is something different than one might think. First, it may be troubling if it is not the officially sanctioned policy-in other words if an official acts outside of his authority in using likability as an admissions criterion. Second, it may be troubling because its vagueness allows officials surreptitiously to use other traits as admissions criteria-religion or ethnicity, for example. If so, the problem is not that likability is an admissions criterion. Rather the problem is that under the guise of considering likability, admissions officials are really admitting or rejecting people based on race or ethnicity. Likability itself may feel like an odd criterion, but one can easily reword what one is after in a more appealing way. Suppose that a policy directs admissions officials to admit students who can work cooperatively with others, for example. An ability to cooperate is useful in many employment settings and is, generally, a useful trait. A school's decision to promote that value hardly seems objectionable. What troubles us, if anything, is the concern that because it is hard to identify people who can work cooperatively with others (there is no test one could take), the discretion necessary for implementing this selection criterion would allow officials to use other traits in its stead-intentionally or unintentionally.

\section{History and Current Social Status: How It Matters}

We have established that drawing distinctions on the basis of attributes that define a group that has been mistreated in the past or is currently of lower status feels morally different than drawing distinctions on the basis of other traits. I say "feels" because we are still exploring why this is so and if this feeling is justified. For ease of exposition, let us call traits that define such a group "HSD" traits-for history of mistreatment or current social 
disadvantage. What makes differentiation on the basis of HSD traits morally different in a way that violates the norm that we should treat people with equal concern and respect? If HSD traits really do make a difference in evaluating whether a distinction is permissible or not, what difference do they make and why?

The fact that HSD traits seem to make a difference has led some commentators to contend that it is the equal treatment of groups rather than the equal treatment of individuals that matters. ${ }^{9}$ Thus, one influential answer to the question of why distinguishing on the basis of HSD traits is different is that the requirement that we treat one another as moral equals forbids establishing or strengthening social castes. Another familiar answer to the question of why we ought to be troubled by policies that draw distinctions among people on the basis of HSD traits is that such groups may lack the ability to affect the political process in a regular and fair way. For example, if blacks are regularly excluded from the political process, it is more likely that laws and policies that distinguish among people will do so in a way that disadvantages blacks. This reconstruction of John Hart Ely's famous account of when and why courts should closely scrutinize laws that affect "discrete and insular minorities" can be extended beyond the context of law. What I term the disproportionate burden argument, considered below, was inspired by Ely's concerns.

\section{Anti-Caste and Disproportionate Burden}

Distinguishing on the basis of HSD traits may be morally different than doing so on the basis of non-HSD traits because the former reinforces or entrenches the caste-like aspects of our society. Laws that disadvantage groups without a social identity-people whose last names begin with A, for example-cannot reinforce a caste as there is no such social group whose status can be harmed or reinforced. In order to ask whether a law, policy, or practice reinforces caste, we must first determine whether the group identified is one to which the concept of caste is relevant. The history of how a group has been treated or its current social status is what largely determines whether we are dealing with such a social group. ${ }^{10}$ One caveat before proceeding: The initial comparison between not hiring someone on the basis of the first letter of her last name and not hiring someone on the basis of her sex led to the hypothesis that the history or current social status of a group defined by a trait makes a moral difference. How and why history and social status matter has yet to be 
determined. I do not mean to say they are determinative; a distinction on the basis of a non-HSD trait can also be wrongful. Rather, the contrast between the cases suggests that history and social status matter. We are mining that insight—not a novel one, but one that has been inadequately explored-to determine why and how. To do so, we are considering two prominent accounts (one being a reconstruction) of when distinction-drawing runs legally afoul of the Equal Protection Clause to see if they shed any light. While both accounts of why and how HSD traits matter are flawed, understanding where they go wrong will guide our inquiry to an alternative.

According to anti-caste approaches, history or current social status matter because they determine, to a large degree, which are the groups whose relative status we must safeguard. This view is appealing in many ways, yet ultimately unsatisfactory. It taps a powerful intuition that laws that disadvantage individual African Americans, for example, are morally troubling because of the social status of African Americans as a group. However, this view does so at the cost of relinquishing the individual nature of a violation. A black man denied an opportunity is wronged because this action contributes to the relative disadvantage of blacks as a group. Though the status of the group may be relevant, as I argue below, it ought to be relevant in a way that allows us to maintain that a wrong is done to the individual and not just to the group. ${ }^{11}$

What about the second explanation, which I term the disproportionate burden account? If drawing distinctions among us is necessary to affect many valuable goals, we would hope that the interests of each of us in not being disadvantaged by such distinction drawing are weighed equally in the political and private processes through which such distinctions are drawn. If some groups find it difficult to have their interests considered in these processes, then we may worry about the fairness of the classifications or differentiations brought to bear. ${ }^{12}$

This Ely-inspired account of why the history of mistreatment of particular groups matters fails to capture something important about how drawing distinctions on the basis of these traits is morally problematic. On this view, any one instance of line drawing that does not adequately consider the interests of a particular group is not problematic. Rather, it is the cumulative disadvantage that is problematic. ${ }^{13}$ After all, there will always be winners and losers with individual policies, particularly in a political process. A problem arises when a "discrete and insular minority" (to use those famous words) is unable to break in so as to insure it is not repeatedly a loser. 
It is the fact that the wrongfulness of any individual policy depends on prior policies that is problematic. Consider the case of a privileged white woman who is denied some job or opportunity because she is a woman. If, up until now, she has not been subject to much line drawing on the basis of sex-and the interests of women have been considered in drawing the distinctions that have affected her-what would this account say about this particular instance? Is it wrong? If so, why? One might say that here she is entitled not to be disadvantaged on the basis of her sex but only because in general the interests of women are not adequately considered in the drawing of distinctions in most policies and laws. If so, the sex discrimination that affects her is wrong only derivatively. Something is thereby lost.

The fact that these sorts of accounts relinquish the individual nature of the wrong of wrongful discrimination is sometimes directly embraced. For example, Glenn Loury argues that the commitment to "race-egalitarianism" that he defends "focuses explicitly on the status of groups." This focus entails, in his view, a rejection of "the precepts of liberal individualism," by which he means "the tendency of thought that seeks to critically assess the justice of a society's distribution of resources solely in terms of the welfare of individuals, while giving no independent weight to the economic or social position of identity-based groups." ${ }^{14}$ While I am quite sympathetic with much of Loury's excellent book, I find his approach sets up a false dichotomy. It is possible to claim that the historical treatment and current social status of the group matter in assessing current policy and still maintain that they also matter in determining whether the policy treats individuals unfairly. To mediate the pull of the claim that group status matters with the intuition that an individual has been wronged, we need to find a way that the group status matters to the determination of how the individual has been treated.

An alternative way to make sense of the intuition that the history of mistreatment of a group matters in the assessment of wrongful discrimination is to notice that the history or current status of the group actually affects what one does in drawing such a distinction. What one does in drawing a distinction on the basis of some characteristic is not just separate people into two or more groups and allocate different treatment on the basis of that distinction. Sometimes one also demeans some of the people one classifies. But not always. The employer who does not hire job applicants whose last names begin with the letter A does not demean this group of people. She may intend to. Perhaps she believes people whose last names begin with A 
are idiots because she has known quite a few over the years. Still, demeaning is partly a conventional act as will be explained below, so her action does not demean people with names beginning with A because there is nothing for her intentions to grab onto.

\section{Discrimination as a Social Fact}

The history or current social status of a group affects what one does in classifying on the basis of a particular trait. When a person or institution separates people on the basis of certain characteristics in certain contexts, the actor not only distinguishes but may also demean some of those affected. If so, distinguishing in this way is wrong.

How might that be so? Meaning can come from three sources: the intent of the speaker, the perception or understanding of the listener, and the context in which the "utterance"15 is made. Philosophers of language debate the relative importance of each of these. Moreover, there is an additional debate that focuses on the relative importance of semantics (the conventionally understood meanings of individual words and sentence structures) versus what are called "pragmatics" (context, use). One philosopher on the pragmatics side uses the following example to illustrate the importance of context. You ask him, "Can you cook?" and he replies, "I am French." While "I am French" normally means that the speaker is of French nationality, in this context it means that the speaker-François Recanati-is a good cook. ${ }^{16}$ Here, what the sentence says is seemingly unconnected to the meaning of the individual words or indeed of the sentence, taken on its own. Whether one thinks, like Recanati, that use, context, and pragmatics are the central determinant of meaning or instead that this sort of case is an exception to the way language generally works-a debate I do not wish to enter hereone thing is clear: Sometimes, at the least, words have a meaning that is unrelated to or goes beyond the ordinary meaning of the words and the sentence structure in which they are used. Recanati is surely right about this case: In that context "I am French" means Recanati is a good cook.

When laws or policies group people on the basis of traits, sometimes the context and culture invest these distinctions with a meaning that other distinctions do not have-but not always. If so, then this meaning-the more complex one that depends in part on culture and context-matters to how we ought to assess the moral significance of the action as a whole. Consider the following example: A school principal issues the order: "Black students 
shall sit on the left side of the auditorium and white students shall sit on the right side of the auditorium." In this example, as first suggested by Paul Brest and later discussed by John Hart Ely, ${ }^{17}$ the principal orders this seating arrangement because he likes the aesthetic effect thereby created. The reason for this contrived example was to elucidate some problems of intent-based understandings of the wrong of wrongful discrimination. When we recognize that the meaning of the principal's order depends not only on his intentions and the meanings of his individual words, but also on their context and the culture in which they are spoken, we see that the problematic nature of this classic example dissipates and our instincts about it are fairly easily accounted for. How should we understand the principal's order? Well, first, it is important to note that it is an order. In addition, it has an effect on the students and other teachers, getting them to do something. This much is uncontroversial.

In addition, and perhaps most salient, the principal demeans the black students. To see how this is so, consider a more loaded example. Suppose the principle had said: "Black students shall sit in the back of the bus and white students shall sit in the front." Separation by race in seating on buses, trains, and so on in our culture is conventionally understood to connote inferiority so that the treatment meted out by this classification is more symbolically loaded than is that of the left versus the right side of the room. This order-blacks in the back-has an effect as well. The principal's order is likely to produce a feeling of being stigmatized in the students. But it is the fact that the order demeans that I want to emphasize. In ordering the blacks to the back of the bus, the principal thereby demeans the black students. ${ }^{18}$ This distinction bears emphasis.

The claim that a classification demeans the black students is easily confused with the claim that they are stigmatized. While the notion of stigma is important, I avoid it because I think it is often used in a way that is ambiguous. Sometimes claims about stigma refer to the effect produced by a classification and other times they refer to what one does in classifyingdemean. The effect of classification refers to the harm suffered by those affected, either psychologically or socially. Brown v. Board of Education's famous assertion that segregating African American public school children "generates a feeling of inferiority as to their status in the community that may affect their hearts and minds in a way unlikely ever to be undone"19 is a classic example of the notion of stigma as a psychological harm. In addition, scholars have emphasized the ways in which groups can be stigmatized socially. For example, Glenn Loury builds on the work of Erving 
Goffman in claiming that blacks are a socially stigmatized racial group, by which he means that "the meanings connoted by race-symbols undermine an observing agent's ability to see their bearers as a person possessing a common humanity with the observer-as 'someone not unlike the rest of us.' "20 Both the conception of stigma as psychological harm and as a social harm emphasize the effect produced by a classification. ${ }^{21}$

What I want to call attention to is different. Rather than emphasize the effect (psychological or social) produced by classification, I claim that sometimes it is wrong to classify because of what one expresses-regardless of whether the person or people affected feel demeaned, stigmatized, or degraded. The term stigma can also be used in this way; one may stigmatize, meaning to demean or degrade. But because the term stigma is more commonly used to call attention to the effects of actions, I find it more confusing than helpful to use here.

Another way of capturing the distinction I am drawing is as follows: an approach that looks at the effect of classification focuses on the harm thereby caused, whereas an approach that looks at what one does in classifying focuses on whether that action is wrong. In my view, classification is sometimes wrong because of what one does in classifying and this wrongness is not reducible to the harm that one may inflict.

\section{Context and Culture Make Drawing Certain Distinctions Demeaning}

Whether distinguishing among people demeans any of those affected is determined by the social context in which the action occurs. In our culture, ordering African Americans to the back of the bus is conventionally understood as denigrating. This is not because there is something worse about the back of the bus, however. Teenagers covet that spot. Ordering blacks to the back of the bus is dramatically different because it is blacks that are ordered to the back and because of the history of racial segregation in public transport and much else in this country. In addition, the fact that one orders blacks to the back makes a difference in what one does-ordering (rather than requesting, for example) has a greater potential to demean.

Other countries-with their own histories-render various sorts of treatment meaningful in much the same way that the back versus the front of the bus is for us. When Nelson Mandela was imprisoned on Robin Island, the black prisoners were required to wear shorts while the white and 
colored prisoners could wear long pants. ${ }^{22}$ This policy demeaned the black prisoners because wearing shorts in postcolonial South Africa was conventionally understood as infantilizing. Notice also that this classification occurs in the context of an order-an exercise of power in which the possibility of demeaning is more likely.

While the left side of the auditorium is not generally understood to be inferior to the right, ${ }^{23}$ merely classifying on the basis of race without there being anything about the context that dilutes or saps the order of racial separation of its demeaning potential, risks, at the least, demeaning. This is because separation on the basis of race has a socially or conventionally understood meaning in our culture-particularly an order of racial separation. It can be neutralized by other aspects of the situation. But if it is not neutralized, it remains charged. For example, were a high school teacher teaching about the Jim Crow era to ask his racially mixed class to separate by race in order to illustrate how this separation felt, the fact that this racial separation takes place in the context of educating the students about racial discrimination changes the meaning of this order. And perhaps it is only a request, as the teacher may be open to allowing students who feel too uncomfortable to opt out-which would further modify the meaning of the teacher's action.

Notice that the way in which social context and culture determine whether an act separating people demeans and thereby wrongfully discriminates operates at two levels. First, and most important, is the following aspect: Whether the characteristic one uses to classify has the potential to demean is determined largely by how that characteristic has been used to separate people in the past and the relative social status of the group defined by the characteristic today. Race is different from the letter that begins one's last name. Second, when we distinguish between people on the basis of some characteristic, we then accord different treatment to each group. Sometimes that different treatment is better or worse in a way that would be true across cultures - loss of a job, health care, education, and so on. Other times, the difference in treatment resides in the cultural significance of that treatment - the back of the bus, wearing shorts, and so on. In these cases, the conventionalism of discrimination occurs at a second level as well.

One caveat before we proceed. Drawing distinctions on the basis of HSD traits has more potential to demean because of the social significance of such distinctions. But as I explained above, not all distinction-drawing on the basis of HSD traits is demeaning, as other aspects of the situation also affect 
whether one demeans. Moreover, categorizing on the basis of non-HSD traits can also demean; however, more contextual factors are required for this to be the case.

Let me recap the argument thus far. To classify (or to draw distinctions among people on the basis of some attribute) is to do several things at once. First, to classify is to distinguish, to separate, to divide. Second, classifying generally produces an effect-different treatment is accorded to different persons and, at times, some of those affected feel stigmatized. Third, in classifying sometimes we demean. It is this third aspect of classification that is crucial and determines whether the action constitutes wrongful discrimination.

Whether classification demeans depends on the social or conventional meaning of drawing a particular distinction in a particular context. Context and culture play a significant role in determining the meaning of actions. Sometimes to classify is to demean-and when it is, this denigration is relevant to its moral permissibility.

\section{Why Demeaning?}

The discrimination puzzle is of moral concern because treating people differently risks running afoul of the idea that people have equal moral worth. We cannot treat all people the same; laws, policies, and practices must draw distinctions among people on various bases. This fact of necessary differentiation gives rise to the moral question of when different treatment is morally permissible and when it is not. When does differentiation fail to treat people as moral equals?

To demean is to treat someone in a way that denies her equal moral worth and thus picks out a wrong that is intimately tied to the value that underlies our worries about differentiation in the first place. To demean is not merely to insult but also to put down, to diminish and denigrate. It is to treat another as lesser. Interestingly, some have argued that demeaning is the core moral wrong, not only relating to differentiation but more generally. Jean Hampton, for example, offers the following as a definition of a moral wrong (as distinguished from mere harm): “A person wrongs another if and only if (while acting as a responsible agent) she treats him in a way that is objectively demeaning." 24 This conception of moral wrong springs from the same intuition that I have offered to explain when and whether differentiation is wrong. After all, people harm one another in many ways. 
If one is trying to distinguish harms that are wrongs from those that are not, one could propose a theory of rights (like bodily integrity, control of property, etc.). Alternatively, one could say that harms that demean are wrongful and harms that do not are benign. Here, the idea of demeaning helps one to identify which harms treat the other in a way that conflicts with the bedrock principle of the equal moral worth of persons.

While I am sympathetic to Hampton's account of moral wrong, I do not want to argue for or against it here. Rather, I point it out to show the reader the general appeal of demeaning as a moral concept. Moreover, I think the more modest claim that demeaning is the core moral concept separating permissible from impermissible differentiation is especially plausible. First, this is because our worries about differentiation spring from the particular concern that in treating people differently we may fail to treat them as moral equals. And second, differentiation occurs in many contexts in which there is no way to define the "right" that someone may otherwise be entitled to (like bodily integrity or use of property). Rather, the employer or school admissions official is free to use whatever criteria he or she wants to decide whom to hire or admit-within limits. These limits are what we are trying to sketch.

Demeaning is not equivalent to subordination. It may lead to subordination, but that is the effect-one that is likely from repeated demeaning actions, but an effect that may not occur. So, in any particular instance, if a person is demeaned by a policy (that distinguishes among people), she need not feel demeaned to have a moral claim. Demeaning is wrong because the fact that people are of equal moral worth requires that we treat them as such. We must not treat each other as lesser beings even when doing so causes no harm. Hampton draws a similar distinction between demeaning and degradation. When one person wrongs another (defined as acting in a way that is "objectively demeaning"), the person wronged may feel that her status has been lowered or she may not. If she does not, "she perceives herself to have suffered no literal degradation as a result of the wrongdoing. Her high value is, she believes, unchanged despite the action. But she is nonetheless demeaned in the sense that she has been forced to endure treatment that is too low for her. So there is a difference between being demeaned and being literally lowered in value." 25

In saying that it is wrong to demean I do not mean to claim that one can never demean. Rather, like other claims of moral right or wrong, it is possible that in a particular instance, one could demean to avoid a worse wrong 
or perhaps a very great harm. Rather, the goal here is to analyze when differentiation is wrong-not to say when the wrongfulness of this action may be overridden by other concerns.

\section{Is Demeaning Enough?}

I have argued that demeaning especially offends against the requirement of treating others as having equal moral worth. To demean is to treat someone as less worthy and to do so in a way that is reasonably powerful. What it takes for an action to demean will be discussed in more detail in Chapter 2 . But, one might wonder, are not there other ways besides demeaning that offend the equal moral worth of others? After all, killing someone surely does (though perhaps it would be more natural to say that killing offends the inherent worth of a person rather than the equal worth of the person). If so, then perhaps demeaning is only one sort of wrongful discrimination and perhaps there are others. The question that is the focus of this book is this: When does drawing distinctions among people fail to respect their equal moral worth? The answer I have argued for in this chapter is that when distinctions demean, they wrongfully fail to treat people as moral equals. This answer leaves open the possibility that some distinctions that do not demean may also fail to treat people as moral equals, but for other reasons. While I cannot conclusively reject this possibility, Chapters 4,5 , and 6 attempt to convince the reader that several promising arguments for thinking that nondemeaning distinctions can also fail to treat those affected as moral equals fail. In Chapter 4, I argue that treating people as equals does not require that distinctions be drawn on the basis of merit. In Chapter 5, I argue that treating people as equals does not require that distinctions be rational. Taking these two arguments together suggests that treating people as moral equals does not require that one have a good reason for distinguishing among people. (I say "suggests" because clearly these two arguments do not cover all possible alternatives, but the fact that they fail is suggestive.) Rather, to classify people in a way that treats them as moral equals, we must simply refrain from doing so in a way that demeans. This is a less demanding requirementdifferentiation need not be justified, it only needs to refrain from demeaning. Respect for the diversity among people, among aims, and among institutions argues for this more modest approach. There is unlikely to be a defined list of permissible reasons to distinguish among people. Rather, there is one clear reason not to. When differentiation demeans it is wrongful. 
When it does not, we ought to let the complexity and diversity of our goals and values flourish.

\section{An Individual Wrong}

This account of wrongful discrimination provides an explanation of why the history and current social status of groups are relevant. At the start of this chapter, I ventured the contrast between not hiring someone because her last name begins with $\mathrm{A}$ and not hiring someone because he is black or she is a woman suggests that distinguishing among people on the basis of HSD traits matters. I then asked why it matters and endeavored to develop a theory to explain the relevance of these HSD traits without losing track of our intuition that wrongful discrimination is an individual wrong. The account provided here satisfies both of these requirements. History and current social status are relevant because they are part of what determines the meaning of a law, policy, or practice that draws distinctions on the basis of a particular trait.

Let us return to our original comparison: discriminating on the basis of the first letter of one's last name versus discriminating on the basis of race or sex. If the school principal were to ask students whose last names begin with the letters A-M to sit on the left side of the auditorium and those whose last names begin with $\mathrm{N}-\mathrm{Z}$ to sit on the right, what does he do in issuing this request or command? He requests or commands but he does not demean. Segregating people on the basis of the first letter of one's name has no social significance in our culture, so that what he does is request or command, but not demean. He does not demean because his request or order does not have a loaded meaning in our culture. This is an interpretive claim about our culture. Of course at that school it is possible that there has been a history of treating people whose last names begin with the letters $\mathrm{A}-\mathrm{M}$ poorly so that the social significance of his command would then demean. But this possibility only emphasizes what it takes to make it the case that in classifying he demeans.

The account presented here avoids another important pitfall in debates about equality. Some influential scholars have claimed that equality is an empty idea-that equality requires simply that persons be treated in accord with how they ought to be treated. ${ }^{26}$ For example, if each of us is entitled to be judged by academic merit when applying to a college or university, then what is wrong with deviations from this norm in some cases is not an of- 
fense against equality but instead an offense against the requirement that academic merit is the right criterion to apply. On this view, the concept of equality is doing no real work. The account of wrongful discrimination provided here avoids this pitfall, giving real teeth to the concept of equality without simultaneously putting forward a controversial conception of positive human rights.

Discrimination is wrong when it demeans. To demean is to treat another as less worthy. In this sense, demeaning is an inherently comparative concept. What will be demeaning will surely vary from context to context and from culture to culture, and thus it is unlikely that a norm of nondemeaning will require that people have access to some particular conception of rights or minimum level of goods. What it does require is that laws, policies, and practices not draw distinctions among people in a way that treats some as less worthy than others, however that is interpreted in that culture. This account thus neither reduces equality to an entitlement to a specific good or right nor leaves it empty of bite or content.

I have presented the view that it is morally wrong to draw distinctions among people and treat them differently as a result when doing so demeans any of those affected. For this account to be convincing, there are important questions that must be addressed. The next two chapters will elaborate the basic idea presented here. First, Chapter 2 will further explore what is demeaning. Next, Chapter 3 will address how one determines whether a particular classification demeans, and what we should say about the fact that people are likely to disagree about whether particular classifications demean. Part II will consider alternative answers to the question of when discrimination is wrong. Chapter 4 argues against the claim that the concept of merit helps determine when a classification fails to treat people as equals. Chapter 5 considers the more modest claim that distinctions must at least be rational. Lastly, Chapter 6 explores and rejects the view that it is the intention of the person who draws a distinction that is important. 


\section{Index}

Accuracy: equal protection and, 115; equality and, 121-123; proxy, failure in, 123-127; prophylaxis and, 130-132; increasing, tightening fit by, 132-134

Actor/speaker: power of, 35, 57, 61, 63; social status of, 35, 36, 37; action and, $36,57,61,198 \mathrm{n} 44$; order v. advice of, 61-63

Actuarial fairness, 115

ADA. See Americans with Disabilities Act Admissions, school, 93, 101, 147; criteria for, 14-18, 19-21, 93, 101, 176n 8

Affirmative action, 79, 80-81, 186n37

Aims, intentions as, 140

Alexander, Larry, 143-149, 157

Alphabetic discrimination, 1, 14, 15-16, 25, 32, 176n6

Americans with Disabilities Act (ADA), 138

Anscombe, G.E.M., 140

Anderson, Elizabeth, 171

Anti-caste approach, 22-25, 177n10

Arbitrariness, 90-91, 134-136

Arneson, Richard, 163, 199n52

Black, Charles, 54-55

Buss, Sarah, 185n26

Canadian law, equality in, 51-54

Classification: meaning and, 25-27; intention and, 26, 27; race-based, 27-28, 40, 64-66, 184n 10; trait-based, 28-29, 57, 142; demeaning definition and, 34-37; rational, definition of, 115; efficiency of, 116; sex-based, rationality and, 117-121; unintentional, 156

Cognitive bias, 143, 151, 155

Cole, Kevin, 146, 157

Coleman, Jules, 71, 76, 77

Common sense merit, 97-101, 187n5

Confirmation bias, 130, 193n37

Constructed merit, 97-101, 187n5

Convention: context and, 38-41; meaning and, 38-41, 45-47; meaning $\mathrm{v}$. practice and, 45-47; disrespect and, 75

Daniels, Norman, 105-106, 108

DDE. See Doctrine of Double Effect

Desert, merit and, 101-105, 108-110, $188 \mathrm{n} 14$

Difference feminism, 55-56, 182n53

Disparate impact, 145-146, 147, 195n21

Disproportionate burden, 22, 23-25

Doctrine of Double Effect (DDE), 151-153, 154,165

Dworkin, Ronald, 80, 175n2, 177n18

Ely, John Hart, 15, 22, 23, 55, 177n12

Equal Protection Clause, 4, 20, 177n11, 178n21; accuracy and, 115; intention and, 139; purpose and, 162-163

Facial discrimination, intent and, 147-149

Fiss, Owen, 15, 175nl

Frankfurt, Harry, 47-48 
Frank, Robert, 49, 181n29

Fried, Barbara, 109, 188n14

Fullinwider, Robert, 97

Goffman, Erving, 26-27

Group: individual equality v., 22, 23, 24, 177n11

Hampton, Jean, 29, 30, 50, 57

Holmes, Oliver Wendell, 140-141, 167, 193n6

Inaccuracy: equality and, 121-123; proxy, 123-127

Intention, 9, 91-92, 138-172; demeaning and, 24-25, 166-167

Interpretive judgment, 69-70, 78-79; objectivity of, 71-75, 76

Kahn, Jonathan, 60, 67

Karst, Kenneth, 56

Kreiger, Linda Hamilton, 141

Lasagna, Louis, 99

Lawrence, Charles, 55, 182n5 1

Leiter, Brian, 71-72, 76, 77

Lichtenberg, Judith, 97

Loury, Glenn, 24, 26-27, 40, 66

Luck, 171-172; egalitarianism, 171; option, 199n2

MacKinnon, Catharine, 55-56, 119-120, $182 \mathrm{n} 53$

Manners, 185n26

Margalit, Avishai, 49, 56-57

McCrudden, Christopher, 95-96, 97, 187n5

Merit, 6, 8, 89-90; moral force of, 94-95; weak form/claim for, 95, 110-112; defining, 95-96; common sense v. constructed, 97-101, 187n5; conceptual instability of, 98; desert and, 101-105, 108-110, 188n14; entitlement/desert and, 101-105, 188n14; efficiency and, 105-108, 188n17; strong principle for, $112-113$

Motives, 140, 194n7; purpose v., 162
Nafisi, Azar, 101; Reading Lolita in Tehran, $17-18,93$

Nagel, Thomas, 82

Objectivity, 69-71; type v. token, 71; of interpretive judgment, 71-75, 76; minimal conception of, 72, 73-74; strong, 74; modest, 75-79; culture and, 79, 82-83; eligibility notion for, 83-84

Pettit, Philip, 75, 78

Physician-assisted suicide, 152-153

Physicians, merit of, 99-100, 187n 10

Postema, Gerald, 71

Post, Robert, 46, 180n 17

Power: actor/speaker's, 35, 57, 61, 63; imbalance of, 61

Practice, conventional meaning v., 45-47

Pragmatics, 25

Principle of Double Effect (PDE), 152

Productive Job Assignment Principle (PJAP), 106, 108

Proxy: inaccurate, 123-127; fit and, 131; intent and, 148; target and, 149, 156-157; race as, 159

Punishment, 49-51

Purpose: motive v., 162; Equal Protection Clause and, 162-163; intention and, 162-166, 198n47

Race: classification based on, 27-28, 40, 64-66, 184n 10; BiDil ambiguity on, 60; sociological/biological basis of, confusion over, 60, 67-68; as proxy, 159

Rationality, 20, 159; definition of, 115

Rawls, John, 109

Raz, Joseph, 82

Réaume, Denise G., 52

Reichman, Amnon, 37, 176n4

Rosati, Connie, 74

Scanlon, Tim, 154, 155, 158

Schauer, Frederick, 123, 128

Scheffler, Samuel, 171

Segregation: seating, principal ordering, 
25-26, 28; social meaning of, 54-55;

racial, 55, 72; single-sex bathrooms and, $59,68-69,72-73,76,77,83$

Semantics, 25

Sex: -based classification, 117-121

Single-sex bathrooms, 59, 68-69, 72-73, $76,77,83$

Social fact, discrimination as, 25-27

Stereotypes: gender-specific, 43, 138; unconscious, 138

Stigma, 26-27; of criminals, 50-51

Subordination, demeaning distinguished from, 30

Sverdik, Steven, 155

Target: proxy and, 149, 156-157; intention and, 157-162. See also Purpose
Transsexuals, demeaning of, 68-69, $72-73$

Unconscious bias, 141-142, 194n10

Unintentional classification, 156

U.S. Constitution: Equal Protection Clause in, 4, 20, 177n11, 178n21; equal protection in, 4

Walen, Alec, 165

Westen, Peter, 47

Williams, Joan, 111

Wolff, Jonathan, 171

Wolff, Robert Paul, 188n21

Wolff, Tobias Barrington, 188n21

Yuracko, Kimberly, 46 